\title{
Chlorhexidine and proanthocyanidin enhance the long-term bond strength of resin-based endodontic sealer
}

\section{Thaís Fantinato TRINDADE ${ }^{(a)}$ Ana Flávia Simões BARBOSA(a) Larissa Moreira Spinola de CASTRO-RAUCCI(a) Yara Teresinha Correa SILVA-SOUSA ${ }^{(a)}$ Vivian COLUCCI(a) Walter RAUCCI-NETO(a)}

(a) Universidade de Ribeirão Preto - Unaerp, School of Dentistry, Ribeirao Preto, SP, Brazil.

Declaration of Interest: The authors certify that they have no commercial or associative interest that represents a conflict of interest in connection with the manuscript.

\section{Corresponding Author:}

Walter Raucci-Neto

E-mail: rauccineto@yahoo.com.br

https://doi.org/10.1590/1807-3107bor-2018.vol32.0044

Submitted: Dec 06, 2017

Accepted for publication: Mar 21, 2018

Last revision: Apr 11, 2018
Abstract: The aim of this study was to evaluate the effects of proanthocyanidin (PA) and chlorhexidine (CHX) on the bond strength (BS), failure pattern, and resin-dentin interface morphology of the endodontic sealers EndoREZ and AH Plus after $24 \mathrm{~h}$ and 6 months of water storage. A total of 120 prepared bovine roots were divided into six groups: $\mathrm{AH}$ Plus, $\mathrm{CHX}+\mathrm{AH}$ Plus, $\mathrm{PA}+\mathrm{AH}$ Plus, EndoREZ, CHX+EndoREZ, and PA+EndoREZ. Dentin was treated for 1 or $5 \mathrm{~min}$ with $2 \%$ CHX or $15 \%$ PA, respectively. Roots were filled and stored in water for $24 \mathrm{~h}$ or 6 months $(\mathrm{n}=10)$. Root slices were subjected to push-out test and scanning electron microscopy (SEM). Data were compared using two-way ANOVA and student's $t$-test $(\alpha=5 \%)$. BS decreased over time for AH Plus and untreated EndoREZ $(p<0.05)$. At $24 \mathrm{~h}$, AH Plus had higher BS than EndoREZ ( $p<0.001)$, with no differences among treatments for both sealers $(p>0.05)$. At 6 months, EndoREZ had higher BS values for CHX and PA than control ( $p<0.05)$. AH Plus had higher BS than EndoREZ ( $p<0.001)$, while with CHX or PA, similar BS was observed in both sealers $(p>0.05)$. Cohesive and mixed failures were observed in all groups. SEM revealed sealer tags in the root dentin. In conclusion, BS decreased with time and AH Plus had higher BS than EndoREZ in untreated dentin; however, CHX or PA enhanced long-term BS of EndoREZ. Overall, dentin treatment affected failure pattern and resin-dentin interface morphology, particularly for EndoREZ.

Keywords: Endodontics; Dental Bonding; Root Canal Obturation.

\section{Introduction}

Significant clinical and scientific evidence supports the use of resin-based sealers in root canal filling, such as their ability to reduce microleakage in the root canal because of their adhesive potential and penetrating ability in the dentinal tubules. ${ }^{1}$ Endodontic sealers based on epoxy resin, such as AH Plus (Dentsply Sirona, Ballaigues, Switzerland), have high apical sealing capacity, biocompatibility, retention capacity to the root dentin, low solubility, and dimensional stability ${ }^{2}$ Methacrylate resin-based sealers, such as EndoREZ (Ultradent, South Jordan, USA), were specifically developed to adhere to the walls of the root canal through the formation of a hybrid layer, thereby reducing infiltration and increasing the seal 
between the root canal and the sealing material. However, methacrylate resin-based sealers may exhibit technical sensitivity, preventing complete hybridization of the tissue. In addition, contraction during the polymerization process can negatively interfere with the sealing and adhesive capacities. ${ }^{3}$ To overcome these limitations which prevent stable dentin adhesion, there has been an intense search for protocols and techniques that favor bonding with the root dentin. $., 5,6,7,8$

The difficulty in achieving a stable hybrid layer with dentin tissue is related to the hydrophilic nature and organic structure of the sealer, ${ }^{9,10}$ which can interfere with the sealer-dentin interaction. ${ }^{11}$ In fact, incomplete infiltration of resinous monomers into collagen fibers within the hybrid layer favors hydrolysis and degradation of collagen by metalloproteinase (MMP), thus reducing the bonding longevity. ${ }^{12}$ MMPs are calcium- and zinc-dependent endopeptidases trapped within the mineralized dentinal matrix during tooth development in an inactive form. The activation of these enzymes can occur after exposure to collagen because of the breakdown of zinc and calcium bonds and is considered one of the main causes of bond failure between resinous materials and dentin. ${ }^{13}$

Self-etch sealers were developed to reduce the sensitivity of the technique, particularly in the apical third, where primer or adhesive is often improperly applied. ${ }^{14}$ The formation of an adhesive interface between the filling material and the dentin occurs after the removal and/or alteration of the smear layer and the demineralization of the underlying dentin. ${ }^{15}$ The process of dentin demineralization using this sealer is directly related to the effects of MMPs on collagen degradation and reduction of bond strength (BS). ${ }^{5}$ However some sealers, such as EndoREZ, possess a hydrophilic primer and do not require the use of acid etching, thereby allowing its application in moist root canals, forming tags for retention in the dentinal tubules. ${ }^{16}$ All manufacturers of methacrylate-based sealers recommend the use of ethylene diamine tetra acetic acid (EDTA) in the final cleaning protocol to expose dentin collagen fibers and to improve infiltration of the resinous monomers in the matrix. Regardless of the sealer composition, this process increases collagen matrix degradation over time. ${ }^{5}$ Thus, the use of MMP inhibition solutions is essential to neutralize the lytic activity of dentin on gelatin and collagen, thus increasing the stability of the hybrid layer. ${ }^{13,17}$

For example, in addition to its well-known antimicrobial properties, chlorhexidine ( $\mathrm{CHX})$ is a protease inhibitor capable of neutralizing MMP and cathepsin cysteine activity, thereby preserving the hybrid layer. ${ }^{12}$ Liu et al. ${ }^{18}$ reported that $\mathrm{CHX}$ is the only proven effective substance that reduces adhesive interface degradation by inhibiting MMPs; however they stated that its action lasts for only a few months and weakens over time. Additionally, proanthocyanidin (PA), a flavonoid compound found in fruits, vegetables, seeds, and flowers, has shown antioxidant capacity ${ }^{5}$ as well as inhibition of the catalytic activity of MMPs, such as MMP-1 and MMP-9; $; 1,19$ thus, PA can be used as an alternative to improve and stabilize collagen resistance against long-term degradation. ${ }^{12,13}$

Considering that the chosen procedure for cleaning the root canal before filling can compromise the longevity and retention of resin sealers, this study was aimed at investigating the use of MMP-inhibitor and crosslinking solutions that neutralize these enzymes while maintaining the integrity of the dentin matrix to improve short- and long-term BS of resin-based endodontic sealers. The null hypothesis was that no differences would be detected in the BS of sealer and/or treatment groups during the experimental periods.

\section{Methodology}

\section{Selection and preparation of specimens}

Bovine incisors stored in $0.1 \%$ thymol solution at $4^{\circ} \mathrm{C}$ were cleaned using periodontal curettes and subjected to prophylaxis with pumice stone (SS White, New Jersey, USA) and water, applied with mounted Robinson brushes at low rotation (Intramatic 2068, Kavo Ind. Com. Ltda., Joinville, Brazil). The teeth were radiographed to measure the cervical, middle, and apical diameters. Averages were obtained and teeth with discrepant measurements were discarded. A stereoscopic magnifying glass (ZEISS, Stemi 2000-C, Germany) at $10 \times$ magnification was used to analyze the teeth and those that had cracks or structural anomalies were excluded from measurement. The teeth were transversely sectioned near the cementum-enamel junction using a 
precision cutting machine set at $375 \mathrm{rpm}$ (IsoMet 1000, Buehler, Germany). A double-faced diamond disc was used to obtain roots with a standardized length of $17 \mathrm{~mm}$ under constant water irrigation. Mesiodistal and buccolingual root canal diameters were measured in the cervical region and samples with mean diameters of 1.5 and $2.5 \mathrm{~mm}$ were selected. One hundred and twenty bovine incisors were used.

\section{Biomechanical preparation of specimens}

A size 15 K-file (Dentsply Sirona, Ballaigues, Switzerland) was passively introduced into each root canal to confirm the working length $(16 \mathrm{~mm})$. Teeth with laterally displaced foramina and/or canal length $<17 \mathrm{~mm}$ were replaced. The root apex was sealed using utility wax and the canals were instrumented using the ProTaper Universal (Dentsply Sirona, Ballaigues, Switzerland) according to the following protocol. Specimens were stabilized in a bench vice. The cervical third was prepared using the SX instrument and the middle and apical thirds were prepared using the S1, $\mathrm{S} 2, \mathrm{~F} 1, \mathrm{~F} 2, \mathrm{~F} 3, \mathrm{~F} 4$, and F5 instruments. The root canals were irrigated with $2 \mathrm{~mL} 2.5 \% \mathrm{NaOCl}$ at each file change using NaviTip needles (Ultradent Products Inc.) attached to plastic syringes (Ultradent Products Inc. South Jordan, USA). A VDW Silver (VDW GmbH, Munich, Germany) was used to operate all files. For the final rinse, the root canals were irrigated with 5 mL 17\% EDTA (Da Terra, Ribeirão Preto, Brazil) for $3 \mathrm{~min}$, irrigated with $5 \mathrm{~mL}$ of distilled water, and dried using sterile absorbent paper cones (\# 50) (Dentsply Sirona, Ballaigues, Switzerland).

\section{Dentin treatment}

After biomechanical preparation, the roots were separated into groups according to the solutions used for dentin treatment. For the groups treated with $2 \%$ CHX (Da Terra, Ribeirão Preto, Brazil), $1 \mathrm{~mL}$ of the solution was applied for $1 \mathrm{~min}$. For groups treated with PA, a 15\% solution was obtained from grape seed extract capsules (Luna Ervas, Caieiras, Brazil) diluted by simple solubilization. One milliliter of PA solution was stirred with a magnetic stirrer (Biovera, Rio de JaneiroBrazil), filtered, and used immediately after solubilization for $5 \mathrm{~min}$. The roots were aspirated and dried using sterile absorbent paper (\# 50) (Dentsply Sirona,
Ballaigues, Switzerland). Untreated dentin specimens were maintained at relative humidity and $37^{\circ} \mathrm{C}$.

\section{Specimen filling}

Roots were filled using cold lateral compaction with gutta-percha F5 master cones (Dentsply Sirona, Ballaigues, Switzerland) and L accessory gutta-percha cones (Dentsply Sirona, Ballaigues, Switzerland) with AH Plus or EndoREZ sealers. The base and catalyst pastes for the AH Plus sealer were dispensed onto a glass plate and mixed until a homogeneous mixture at an ideal consistency for filling was obtained. The gutta-percha cone was loaded with the sealer and inserted into the root canal. In groups filled with EndoREZ, $30 \mathrm{~g}$ sealer was injected through a self-mixing tip into a syringe applicator and inserted into the canal using 21-mm yellow NaviTip tips until reaching the apex. The gutta-percha cone was inserted into the root canal after filling it with the sealer. The cone was then cut using a heated instrument and vertically condensed with a plugger (Duflex, SS White, New Jersey, USA). Excess sealer was removed using cotton pellets. After filling, specimens filled with EndoREZ were photopolymerized for $40 \mathrm{~s}$ and all specimens were filled with temporary restorative material without eugenol (Villevie, Nova Brasília, Joinville, SC, Brazil). The teeth were immediately placed at $37^{\circ} \mathrm{C}$ and relative humidity for 3 times longer duration than the regular setting duration for the sealer.

\section{Water storage}

Specimens were further separated into two subgroups based on storage time in water ( $24 \mathrm{~h}$ and 6 months). The roots were maintained in Eppendorf tubes with $1.5 \mathrm{~mL}$ distilled water at $37^{\circ} \mathrm{C}$; water was changed on a weekly basis for the 6-month group. ${ }^{20}$

\section{Bond strength test (Push-out)}

The roots were fixed onto acrylic plates using wax (Kota-Import, São Paulo, Brazil) and sectioned using a precision cutting machine set at $375 \mathrm{rpm}$ and equipped with a water-cooling system. Nine $1.5 \mathrm{~mm}$-thick slices were obtained from each root (3 per root-third), resulting in a total of 1,080 specimens. The middle slice from each third canal was selected 
and mounted on a stainless steel support used to hold the specimens in an Instron 3345 Universal Testing Machine (Instron Corporation, Canton, USA) in such a way that the side with the smaller root canal diameter faced upward and was aligned to the shaft that would exert pressure on the sealer (apex-crown direction) until debonding occurred. Six-millimeterlong shafts with tip diameters of $0.6 \mathrm{~mm}$ for the apical third, $0.8 \mathrm{~mm}$ for the middle third, and $1 \mathrm{~mm}$ for the coronal third were used. This method assured the alignment of the specimen in an accurate and reproducible manner and also enabled the shaft to remain centralized and avoid contact with dentin during testing. The force required to dislodge the filling material ( $\mathrm{F}$ in $\mathrm{kN}$ ) was transformed into tension ( $\sigma$ in $\mathrm{MPa}$ ) by dividing the force by the adhesive area of the filling material (SL in $\mathrm{mm}^{2}$ ) using the equation $\sigma=\mathrm{F} / \mathrm{A}$. After the push-out test, the slices were examined using a stereomicroscope (ZEISS, Stemi 2000-C, Germany) at 25× magnification to determine the failure pattern. Failure was considered adhesive if the sealer was completely separated from the dentin (dentin surface without sealer), cohesive if the fracture occurred within the sealer (dentin surface completely covered by the sealer), and mixed when a mixture of adhesive and cohesive modes occurred (i.e., the dentin surface was partially covered by the sealer), according to Haragushiku et al. ${ }^{17}$

\section{Scanning electron microscopy}

The third slice obtained from each canal third was prepared for scanning electron microscopy (SEM) analysis of the filling material/radicular dentin interface. The slices were immersed in 2.5\% glutaraldehyde (Merck KGaA, Darmstadt, Germany) with 0.1-M sodium cacodylate buffer solution ( $\mathrm{pH}$ 7.4) (Merck KGaA) for $12 \mathrm{~h}$ at $4^{\circ} \mathrm{C}$. After fixation, the specimens were rinsed using 0.1-M sodium cacodylate buffer solution and then sequentially dehydrated in increasing concentrations of ethanol solutions (Labsynth Produtos para Laboratório Ltda., Diadema, Brazil) as follows: $25 \%$ for $20 \mathrm{~min}, 50 \%$ for $20 \mathrm{~min}, 75 \%$ for $20 \mathrm{~min}, 90 \%$ for $30 \mathrm{~min}$, and $100 \%$ for $60 \mathrm{~min}$, after which they were immersed in a hexamethyldisilane solution (HMDS, Ted Pella, Redding, USA) for $10 \mathrm{~min}$. The specimens were then placed on an absorbent paper on glass plates and allowed to dry under an exhaust hood for $24 \mathrm{~h}$. The specimens were mounted on metallic stubs, sputter-coated with gold-palladium alloy (SDC 050; Bal-TecAG, Balzers, Liechtenstein) and examined in an SEM (JSM T330A, JEOL Ltd, Tokyo 190-0012, Japan) operating at $20 \mathrm{kV}$. SEM micrographs at $500 \times$ magnification were obtained from four distinct points at the perimeter of the root canal. Qualitative analysis of adhesive interfaces included studying the following characteristics: 1) presence of failure at the interface (gaps) and 2) formation of an extension of sealer into the tubules (tags). ${ }^{18}$

\section{Statistical analysis}

Quantitative data was subjected to normality and variance homogeneity tests. The effects of the sealers and treatments on BS were evaluated using two-way ANOVA, followed by Tukey test when appropriate. The comparison between BS obtained at $24 \mathrm{~h}$ and 6 months in each experimental group was conducted using student's $t$-test. The level of significance adopted was $5 \%$.

\section{Results}

\section{Push-out test}

At $24 \mathrm{~h}$, there was no interaction between the sealer and treatment factors $(p=0.784)$. Overall, a significant difference between the sealers was verified, with the BS of AH Plus > EndoREZ regardless of the treatment $(\mathrm{p}<0.001)$, while no significant differences were observed between the treatments used, regardless of the sealer applied $(p=0.930)$. BS results of the 24 -hour water storage treatment are summarized in Table 1.

At 6 months, there was interaction between the factors under study, i.e., the effect of the sealers varied according to the treatment used $(p=0.012)$. Comparison among treatments revealed the following: for AH Plus, Control $=\mathrm{CHX}=\mathrm{PA}(\mathrm{p}>0.05)$ and for EndoREZ, $\mathrm{CHX}=\mathrm{PA}>\mathrm{Control}(\mathrm{p}<0.05)$. Comparison between sealers showed the following results: for Control, AH Plus > EndoREZ $(p<0.001)$ and for CHX and PA, AH Plus $=$ EndoREZ $(p=332$ and $p=0.089$, respectively). BS results for $24 \mathrm{~h}$ and 6 month water storage are given in Table 1. 
Table 1. Mean values \pm standard deviation of Bond Strength (BS) values obtained in root dentin pretreated or not (Control) with Chlorhexidine (CHX) or Proanthocyanidin (PA) and sealed with AH Plus or EndoRez, after $24 \mathrm{~h}$ or 6 months of water immersion.

\begin{tabular}{lcccccc}
\hline \multirow{2}{*}{ Variable } & \multicolumn{3}{c}{ AH Plus } & \multicolumn{2}{c}{ EndoRez } \\
\cline { 2 - 7 } & Control & $\mathrm{CHX}$ & $\mathrm{PA}$ & Control & $\mathrm{CHX}$ & $\mathrm{PA}$ \\
\hline $24 \mathrm{~h}$ & $0.54 \pm 0.09 \mathrm{Aa}^{*}$ & $0.54 \pm 0.11 \mathrm{Aa}^{*}$ & $0.55 \pm 0.08 \mathrm{Aa}^{*}$ & $0.33 \pm 0.09 \mathrm{Ab}^{*}$ & $0.32 \pm 0.11 \mathrm{Ab}$ & $0.30 \pm 0.06 \mathrm{Ab}$ \\
6 months & $0.43 \pm 0.11 \mathrm{Aa}$ & $0.36 \pm 0.10 \mathrm{Aa}$ & $0.41 \pm 0.10 \mathrm{Aa}$ & $0.21 \pm 0.05 \mathrm{Ab}$ & $0.32 \pm 0.11 \mathrm{Ba}$ & $0.33 \pm 0.10 \mathrm{Ba}$ \\
\hline
\end{tabular}

Capital letters indicate statistical difference among treatments (Control $\times \mathrm{CHX} \times \mathrm{PA}$ ) in the same sealer and time point (two-way ANOVA, $p<$

0.05). Lowercase letters indicate statistical difference between sealers (AH Plus $x$ EndoRez) in the same treatment and time point (two-way ANOVA, $p$

$<0.05)$. Asterisks indicate statistical difference between time points $(24 \mathrm{~h} \times 6$ months $)$ in the same experimental group $(t$-test, $p<0.05)$.

Table 2. Failure mode distribution (\%) in the specimens of root dentin pretreated or not (Control) with $\mathrm{Chlorhexidine} \mathrm{(CHX)} \mathrm{or}$ Proanthocyanidin (PA) and sealed with AH Plus or EndoRez, after $24 \mathrm{~h}$ or 6 months of water immersion

\begin{tabular}{|c|c|c|c|c|c|c|}
\hline \multirow{2}{*}{$\begin{array}{l}\text { Experimental } \\
\text { groups }\end{array}$} & \multicolumn{3}{|c|}{24 hours } & \multicolumn{3}{|c|}{6 months } \\
\hline & Adhesive & Mixed & Cohesive & Adhesive & Mixed & Cohesive \\
\hline AH Plus & 20 & 56.7 & 23.3 & 0 & 70 & 30 \\
\hline $\mathrm{AH}$ Plus $+\mathrm{CHX}$ & 3.3 & 76.7 & 20 & 6.7 & 63.3 & 30 \\
\hline $\mathrm{AH}$ Plus + PA & 3.3 & 40 & 56.7 & 0 & 60 & 40 \\
\hline EndoRez & 30 & 20 & 50 & 6.7 & 73.3 & 20 \\
\hline EndoRez + CHX & 16.7 & 20 & 63.3 & 0 & 63.3 & 36.7 \\
\hline EndoRez + PA & 0 & 30 & 70 & 6.7 & 83.3 & 10 \\
\hline
\end{tabular}

\section{Failure mode after the push-out test}

The failure pattern analysis revealed lower adhesive and cohesive failures for AHPlus than those for EndoREZ at both time points. CHX and PA affected the sealers' failure pattern; at $24 \mathrm{~h}$, both treatments resulted in lower adhesive failures for AH Plus and EndoREZ. However, AHPlus with CHX had higher mixed failures and with PA higher cohesive failures than those of the control group. EndoREZ with CHX had higher cohesive failures and with PA higher cohesive and mixed failures. At 6 months of water storage, $\mathrm{CHX}$ resulted in lower adhesive and mixed failures for EndoREZ than those with control. Also, AH Plus with CHX resulted in higher adhesive failures and PA resulted in higher cohesive failures than those with control. Failure mode distribution in the specimens is displayed in Table 2.

\section{Scanning electron microscopy analysis}

Morphological analysis enabled the evaluation of the filling material-root canal interface. SEM micrographs showed the formation of long tags in the adhesive interface for most sealers except for some samples of $\mathrm{AH}$ Plus where this characteristic was not observed (Figure).

\section{Discussion}

According to the results, the null hypothesis has to be rejected because BS differences were observed between the sealer and/or treatment groups during the evaluated periods. In general, AH Plus sealer exhibited higher BS than EndoREZ when no pretreatment was applied, and CHX or PA improved the BS of EndoREZ after 6 months of storage in water.

It was previously reported that the BS of endodontic filling materials should be as high as possible, not only to ensure efficient root canal sealing but also to ensure long-term endodontic treatment success. ${ }^{6,21,22}$ Furthermore, the bonding interface must remain intact over time and not compromise clinical procedures, such as the removal of part of the sealing material for the installation of root canal posts, because the teeth are subjected to mechanical forces that can displace the sealing material beyond root canal limits. ${ }^{23,24}$ Therefore, in the present study, the BS of the filling material was evaluated after $24 \mathrm{~h}$ and 6 months of storage in water.

The push-out test is widely used to simulate clinical conditions and represents a reproducible method with 

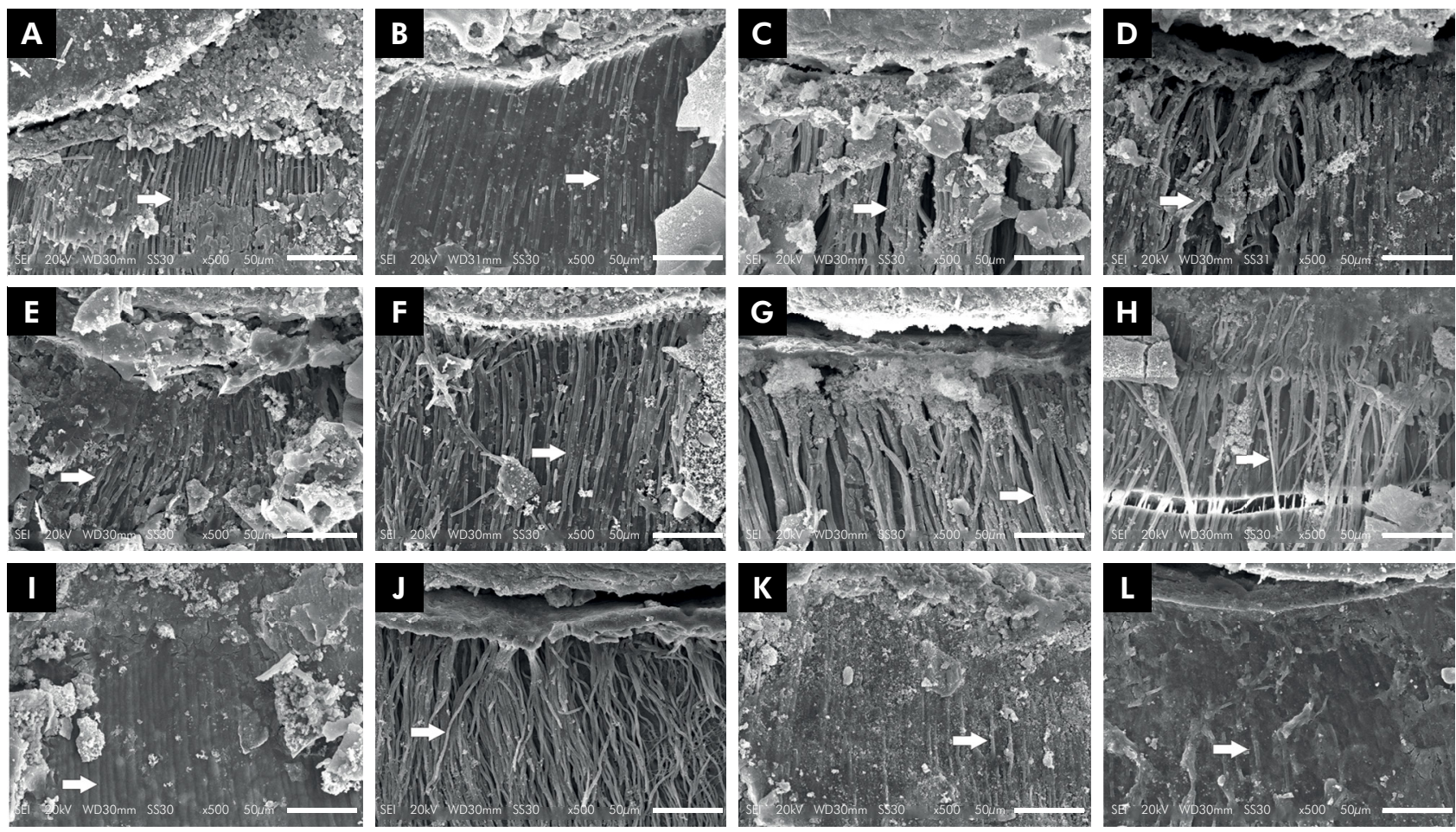

Figure. Scanning electron microscope photomicrograph of resin-dentin interface in $A H$ Plus ( $A$ and $B), A H P l u s+C H X(C$ and $D)$, $A H$ Plus + PA ( $E$ and F), EndoREZ ( $G$ and H), EndoREZ+CHX (I and J), and EndoREZ+PA (K and L) after $24 \mathrm{~h}(\mathrm{~A}, \mathrm{C}, \mathrm{E}, \mathrm{G}, \mathrm{I}$ and $\mathrm{K})$ or 6 months $(B, D, F, H, J$ and $L)$ of water storage. Note the formation of sealer tags for all experimental groups at both time points (indicated with arrows). Magnification: 500x.

fidelity in results. ${ }^{24,25,26,27}$ However, this method is limited by the standardization of specimen positioning, which is essential for reproducibility ${ }^{8}$. In the present study, specimens were positioned upright to the dentinal tubules, which act as a retaining force within the root canal. ${ }^{28}$ In addition, the force application rod was positioned in the center of the filling mass, thus preventing contact with dentin ${ }^{7}$ and favoring a more accurate measurement of material retention.

The results of the 24-hour immediate push-out test showed that the BS of both types of sealers were not influenced by dentin surface pretreatment. Similar results were reported by Kalra et al., ${ }^{5}$ who pretreated dentin with $6.5 \%$ PA and filled the root canals with self-etching sealers; differences in the BS following 1 week of storage in water were not observed. Similarly, Cecchin et al. ${ }^{29}$ reported that pretreatment of dentin with $2 \% \mathrm{CHX}$ yielded no significant effect on the BS of the resin sealer at the immediate level. These findings may be related to inadequate activation time of MMPs during this period because the exposed dentin collagen matrix is slowly degraded by proteolytic enzymes. ${ }^{13}$

In the 6-month water storage group, both $\mathrm{CHX}$ and PA treatments resulted in higher BS values only for the EndoREZ sealer as compared to the control group. These results indicate that specimens sealed with EndoREZ and treated with CHX or PA had stable BS over time. In contrast, this benefit was significantly limited to those with 6 months of storage in water from the control group. These findings are in agreement with those of Kalra et al., ${ }^{5}$ who observed that the use of PA facilitated an increase in the resistance to biodegradation at the interface of the methacrylate-based RealSeal SE sealer. This process promoted the maintenance of BS values, with similar values after 1 week or 3 months of storage in water. Hass et al. ${ }^{30}$ also evaluated the effects of PA on the degradation of the hybrid layer and observed that PA tightened the collagen polypeptides and inactivated catalytic activity of proteases, creating peptide binding with adjacent peptides. Regarding the positive $\mathrm{CHX}$ 
results, studies have demonstrated advantages in its application. Cecchin et al. ${ }^{31}$, for instance, observed that the application of $2 \% \mathrm{CHX}$ prior to fiberglass post filling resulted in maintenance of BS after 12 months of storage in water. Nawareg et al..$^{32}$ also used $2 \%$ CHX and observed stable BS between composite resin and dentin after storage in water for 6 and 12 months. Both authors attribute these results to the inhibition of MMPs by CHX, which favors the stabilization of the hybrid layer. ${ }^{12,18,31}$

In contrast to the methacrylate sealer, $\mathrm{AH}$ Plus showed no effects of CHX or PA on BS after 6 months of storage in water, showing significantly lower values than storage in water for $24 \mathrm{~h}$. These results were not expected because both $\mathrm{CHX}$ and PA reduce the effects of dentin collagen biodegradation, ${ }^{5,7}$ which would maintain chemical bond stability of the sealer over time. However, for the AH Plus sealer, variables other than collagen degradation may have interfered with BS, such as sealer solubility and destabilization of the covalent bonds formed between the AH Plus sealer and dentin collagen over time. ${ }^{33}$

In the comparison between the sealer groups, significantly higher BS was observed in the specimens filled with AH Plus than those filled with EndoREZ after $24 \mathrm{~h}$ of storage in water, regardless of the treatment. After 6 months, these differences were maintained in the control groups; however, the BS of the EndoREZ sealer with CHX and PA were equivalent to that of all AH Plus groups. The stability of the AH Plus sealer ${ }^{1,33}$ may be one of the factors that allows satisfactory resistance values to be obtained, even after storage over a long period. In fact, similar results were described by Haragushiku et al., ${ }^{17}$ who speculated that the lower BS values of EndoREZ are because of its incomplete polymerization and the polymerization contraction inherent in this sealer.
Another factor that has been evaluated for its influence on the BS of endodontic sealers to the root canal is sealer penetration into the dentin tubules ${ }^{34}$. In the present study, SEM analysis revealed the formation of long tags for both types of sealers regardless of the evaluated period, which could indicate the absence of a relationship between the formation of tags and the BS of the sealers. Corroborating this hypothesis, Neelakantan et al. ${ }^{25}$ observed that the penetration of the tags had no relationship with the sealing capacity and the BS of the AH Plus. Nevertheless, according to Doyle et al., ${ }^{4}$ the formation of long resin tags may not provide sufficient strength to resist the polymerization contraction process experienced by EndoREZ, which could explain the lower BS values than those of AH Plus.

Regarding the hypothesis of the current study, it was observed that the root dentin treatment using PA and CHX provided stable BS for the methacrylate sealer EndoREZ and did not affect this evaluation parameter in the resin sealer AH Plus. However, further studies are required to evaluate the chemical stability of the bonds between the filling material and root dentin and the ability of the sealers to seal the root canal system in the long term.

\section{Conclusion}

Based on the results of the current study, it was concluded that BS decreased over time and AH Plus exhibited higher BS than EndoREZ in untreated dentin. However, dentin pretreatment with CHX ( $2 \%$ ) or PA (15\%) stabilized the BS of EndoREZ over time with values similar to those of AH Plus, without interfering with the BS of AH Plus. In addition, dentin treatment protocols affected failure pattern and resin-dentin interface morphology, particularly for EndoREZ.

\section{References}

\footnotetext{
1. Prado M, Simão RA, Gomes BP. A microleakage study of guttapercha/AH Plus and Resilon/Real self-etch systems after different irrigation protocols. J Appl Oral Sci. 2014 Jun;22(3):174-9. https://doi.org/10.1590/1678-775720130174
}

\footnotetext{
2. Razmi H, Bolhari B, Karamzadeh Dashti N, Fazlyab M. The effect of canal dryness on bond strenght of bioceramic and epoxy-resin sealers after irrigation with sodium hypochlorite or chlorexidine. Iran Endod J. 2016;11(2):129-33. PMID:27141222
} 
3. Neelakantan P, Subbarao C, Subbarao CV, De-Deus G, Zehnder M. The impact of root dentine conditioning on sealing ability and push-out bond strength of an epoxy resin root canal sealer. Int Endod J. 2011 Jun;44(6):491-8. https://doi.org/10.1111/j.1365-2591.2010.01848.x

4. Doyle MD, Loushine RJ, Agee KA, Gillespie WT, Weller RN, Pashley DH et al. Improving the performance of EndoRez root canal sealer with a dual-cured two-step self-etch adhesive. I. Adhesive strength to dentin. J Endod. 2006 Aug;32(8):766-70. https://doi.org/10.1016/i.joen.2005.11.003

5. Kalra M, lqbal K, Nitisusanta LI, Daood U, Sum CP, Fawzy AS. The effect of proanthocyanidins on the bond strength and durability of resin sealer to root dentine. Int Endod J. 2013 Feb;46(2):169-78. https://doi.org/10.1111/j.1365-2591.2012.02106.x

6. Ayrancı LB, Köseoğlu M. The evalution of the effects of different irrigating solutions and laser systems on adhesion of resin-based root canal sealers. Photomed Laser Surg. 2014 Mar;32(3):152-9. https://doi.org/10.1089/pho.2013.3606

7. Cecchin D, Pin LC, Farina AP, Souza M, Vidal CM, Bello YD et al. Bond strength between fiber posts and root dentin treated with natural crosslinkers. J Endod. 2015 Oct;41(10):1667-71. https://doi.org/10.1016/i.joen.2015.05.022

8. Khoroushi M, Sheikhi M, Khalilian-Gourtani A, Soleimani $B$. Effect of root canal rinsing protocol on dentin bond strength of two resin cements using three different method of test. J Clin Exp Dent. 2016 Jul;8(3):e246-54. https://doi.org/10.4317/jced.52674

9. Moreira MA, Souza NO, Sousa RS, Freitas DQ, Lemos MV, De Paula DM et al. Efficacy of new natural biomodification agents from Anacardiaceae extracts on dentin collagen cross-linking. Dent Mater. 2017 Oct;33(10):1103-9. https://doi.org/10.1016/i.dental.2017.07.003

10. Wang TF, Feng XW, Gao YX, Wang M, Wang YN, Sa $Y$ et al. Effects of different concentrations and exposure time of sodium hypochlorite on the structural, compositional and mechanical properties of human dentin. J Huazhong Univ Sci Technolog Med Sci. 2017 Aug;37(4):568-76. https://doi.org/10.1007/s11596-017-1774-0

11. Trindade TF, Moura LK, Raucci W, Messias DC, Colucci V. Bonding effectiveness of universal adhesive to intracoronal bleached dentin treated with sodium ascorbate. Braz Dent J. 2016 May-Jun;27(3):303-8. https://doi.org/10.1590/0103-6440201600647

12. Perdigão J, Reis A, Loguercio AD. Dentin adhesion and MMPs: a comprehesive review. J Esthet Restor Dent. 2013 Aug;25(4):219-41. https://doi.org/10.1111/jerd.12016

13. Longhi M, Cerroni L. Condò SG, Ariano V, Pasquantonio G. The effects of hosts derived metalloproteinases on dentin bond and the role of MMPs inhibitors on dentin matrix degradation. Oral Implantol (Rome). 2015 Apr;7(3):71-9.
14. Shrestha D, Wei X, Wu WC, Ling JQ. Resilon: a methacrylate resin-based obturation system. J Dent Sci. 2010 Jun;5(2):47-52. https://doi.org/10.1016/S1991-7902(10)60008-6

15. Amaral RC, Stanislawczuk R, Zander-Grande C, Michel MD, Reis A, Loguercio AD. Active application improves the bonding performance of self-etch adhesives to dentin. J Dent. 2009 Jan;37(1):82-90. https://doi.org/10.1016/i.jdent.2008.09.010

16. Kim YK, Grandini S, Ames JM, Gu LS, Kim SK, Pashley $\mathrm{DH}$ et al. Critical review on methacrylate resin-based root canal sealers. J Endod. 2010 Mar;36(3):383-99. https://doi.org/10.1016/i.joen.2009.10.023

17. Haragushiku GA, Teixeira CS, Furuse AY, Sousa YT, De Sousa Neto MD, Silva RG. Analysis of the interface and bond strength of resin-based endodontic cements to root dentin. Microsc Res Tech. 2012 May;75(5):655-61. https://doi.org/10.1002/jemt.21107

18. Liu RR, Fang M, Zhang L, Tang CF, Dou Q, Chen JH. Antiproteolytic capacity and bonding durability of proanthocyanidinbiomodified demineralized dentin matrix. Int J Oral Sci. 2014 Sep;6(3):168-74. https://doi.org/10.1038/ijos.2014.22

19. Khaddam M, Salmon B, Le Denmat D, Tjaderhane L, Menashi S, Chaussain $\mathrm{C}$ et al. Grape seed extracts inhibit dentin matrix degradation by MMP-3. Front Physiol. 2014 Oct;5(5):425. https://doi.org/10.3389/fphys.2014.00425

20. Colucci V, Loiola ABA, Motta DS, Amaral FL, Pécora JD, Corona SA. Influence of long-term water storage and thermocycling on shear bond strength of glass-ionomer cement to Er:YAG laser-prepared dentin. J Adhes Dent. 2014 Feb;16(1):35-9. https://doi.org/10.3290/j.jad.a30539

21. Franceschini KA, Silva-Sousa YT, Lopes FC, Pereira RD, Palma-Dibb RG, Sousa-Neto MD. Bond strength of epoxy resin-based root canal sealer to human root dentin irradiated with Er,Cr:YSGG laser. Lasers Surg Med. 2016 Dec;48(10):985-94. https://doi.org/10.1002/Ism.22496

22. Vivan RR, Guerreiro-Tanomaru JM, Bernardes RA, Reis JM, Hungaro Duarte MA, Tanomaru-Filho M. Effect of ultrasonic tip and root-end filling material on bond strength. Clin Oral Investig. 2016 Nov;20(8):2007-11. https://doi.org/10.1007/s00784-015-1708-9

23. Marques JH, Silva-Sousa YT, Rached-Júnior FJ, Mazzi-Chaves JF, Miranda CE, Silva $\mathrm{SR}$ et al. New methodology to evaluate bond strength of rootend filling materials. Braz Dent J. 2015 May-Jun;26(3):288-91. https://doi.org/10.1590/0103-6440201300189

24. Vivan RR, Guerreiro-Tanomaru JM, Bosso-Martelo R, Costa BC, Duarte MA, TanomaruFilho M. Push-out bonds strength of root-end filling materials. Braz Dent J. 2016 May-Jun;27(3):332-5. https://doi.org/10.1590/0103-6440201600340

25. Neelakantan P, Sharma S, Shemesh H, Wesselink PR. Influence of irrigation sequence on the adhesion of root canal sealers to dentin: A Fourier Transform 
Infrared Spectroscopy and Push-out bond strength

analysis. J Endod. 2015 Jul;41(7):1108-11.

https://doi.org/10.1016/i.joen.2015.02.001

26. Gandhi B, Bollineni S, Janga RK, Saraswati D, Babu MR.

Evaluating the effect of CPP-ACP as a final irrigant in improving the microhardness of erosive root dentin and its influence on the bond strength of self-etch resin sealer- an in vitro study. J Clin Diagn Res. 2016 Aug;10(8):ZC53-6. https://doi.org/10.7860/JCDR/2016/20819.8272

27. Rached-Júnior FJA, Souza AM, Macedo LMD, Raucci-Neto W, Baratto-Filho F, Silva BM, Silva-Sousa YTC. Effect of root canal filling techniques on the bond strength of epoxy resin-based sealers. Braz Oral Res. 2016;30(1):e24. https://doi.org/10.1590/1807-3107BOR-2016.vol30.0024

28. Sousa-Neto MD, Silva Coelho FI, Marchesan MA, Alfredo E, Silva-Sousa YT. Ex vivo study of the adhesion of an epoxy-based sealer to human dentine submitted to irradiation with $\mathrm{Er}$ : YAG and $\mathrm{Nd}$ : YAG lasers. Int Endod J. 2005 Dec;38(12):866-70. https://doi.org/10.1111/j.1365-2591.2005.01027.x

29. Cecchin D, Farina AP, Giacomin M, Vidal CM, Carlini-Júnior B, Ferraz CC. Influence of chlorhexidine application time on the bond strength between fiber posts and dentin. J Endod. 2014 Dec;40(12):2045-8. https://doi.org/10.1016/i.joen.2014.08.019
30. Hass V, Luque-Martinez I, Muñoz MA, Reyes MF, Abuna G, Sinhoreti MA et al. The effect of proanthocyanidincontaining 10\% phosphoric acid on bonding properties and MMP inhibition. Dent Mater. 2016 Mar;32(3):468-75. https://doi.org/10.1016/i.dental.2015.12.007

31. Cecchin D, Farina AP, Giacomin M, Vidal CM. Carlini-Júnior B, Ferraz CCR. Influence of chlorexidine application time on the bond strenght between fiber posts and dentin. J Endod. 2014 Dec;40(12):2045-8. https://doi.org/10.1016/j.joen.2014.08.019

32. Abu Nawareg M, Elkassas D, Zidan A, Abuelenain D, Abu Haimed T, Hassan AH et al. Is chlorhexidine-methacrylate as effective as chlorhexidine digluconate in preserving resin dentin interfaces? J Dent. 2016 Feb;45:7-13. https://doi.org/10.1016/i.jdent.2015.11.002

33. Silva EJ, Perez R, Valentim RM, Belladonna FG, De-Deus GA, Lima IC et al. Dissolution, dislocation and dimensional changes of endodontic sealers after a solubility challenge: a micro-CT approach. Int Endod J. 2017 Apr;50(4):407-14. https://doi.org/10.1111/iej.12636

34. Cakici F, Cakici EB, Ceyhanli KT, Celik E, Kucukekenci FF, Gunseren AO. Evaluation of bond strength of various epoxy resin based sealers in oval shaped root canals. BMC Oral Health. 2016 Sep;16(1):106. https://doi.org/10.1186/s12903-016-0301-1 